\title{
Evolutions in the Management of Hepatocellular Carcinoma over Last 4 Decades: An Analysis from the 100 Most Influential Articles in the Field
}

\author{
Gang Xu ${ }^{a}$ Bao Jin ${ }^{a}$ Xiaomeng Xian ${ }^{a}$ Huayu Yang ${ }^{a}$ Haitao Zhao ${ }^{a}$ \\ Shunda Du ${ }^{a}$ Masatoshi Makuuchi ${ }^{b}$ Timothy M. Pawlik ${ }^{c}$ Yilei Mao $^{a}$ \\ aDepartment of Liver Surgery, Peking Union Medical College (PUMC) Hospital, PUMC and Chinese Academy of \\ Medical Sciences, Beijing, China; ${ }^{b}$ President of the Koto Hospital, Tokyo, Japan; 'Department of Surgery, Wexner \\ Medical Center, The Ohio State University, Columbus, OH, USA
}

\section{Keywords}

Hepatocellular carcinoma - Management - Treatment ·

Bibliometric analysis

\begin{abstract}
Introduction: Over the past 4 decades, the management of hepatocellular carcinoma (HCC) has changed dramatically. The publications that have had the most significant impact on HCC management have not been quantitatively analyzed. In this article, we analyzed the 100 most influential articles over the past 4 decades using bibliometric citation analysis to characterize the evolution in HCC treatment. Methods: The top-cited publications were identified and analyzed from the Clarivate Analytics Web of Science Core Collection database. Results: The 100 most cited articles were identified with an average of 738 citations (range: 349$6,799)$. There was an increase in the number of influential articles in the late 1990s, which was paralleled by an increase in reports focused on locoregional treatment of HCC. Most top 100 articles came from the USA $(n=35)$, followed by Italy $(n=28)$, mainland China $(n=26)$, and Japan $(n=24)$. The surgical management was the most studied topic $(n=33)$. The Annals of Surgery published the highest number of pa-
\end{abstract}

Gang Xu and Bao Jin contributed equally to this work.

karger@karger.com www.karger.com/lic

Karger $\stackrel{\text { ' }}{=}$

GOPEN ACCESS
(C) 2021 The Author(s)

Published by S. Karger AG, Basel

This article is licensed under the Creative Commons AttributionNonCommercial-NoDerivatives 4.0 International License (CC BY NC-ND) (http://www.karger.com/Services/OpenAccessLicense). Usage and distribution for commercial purposes as well as any distribution of modified material requires written permission. pers ( $n=26)$ with 13,978 citations. While other 3 topics (surgical management, locoregional treatment, and outcome prediction) declined among publications beginning in the 2000s, there was an emergence of highly cited papers on targeted drugs and immune checkpoint inhibitors with a concomitant increase in the number of publications on systemic therapy. Conclusions: Based on bibliometric analysis of the literature over the last 40 years, a comprehensive analysis of the most historically significant HCC management articles highlighted the key contributions made to the evolution and advancement of this specialist field. The data should provide clinicians and researchers insight into future directions relative to the advancement of HCC management.

(c) 2021 The Author(s)

Published by S. Karger AG, Basel

\section{Introduction}

Liver cancer is the sixth most commonly diagnosed cancer and the fourth leading cause of cancer-related death worldwide, with approximately 841,000 new cases and 782,000 deaths per annum [1]. Hepatocellular

Yilei Mao

Department of Liver Surgery, Peking Union Medical College (PUMC) Hospital PUMC and Chinese Academy of Medical Sciences

Beijing 100730 (China)

pumch-liver@hotmail.com

Timothy Pawlik

Department of Surgery

The Ohio State University, Wexner Medical Center

Columbus, $\mathrm{OH}$ (USA)

tim.pawlik@osumc.edu

Prof. Masatoshi Makuuchi, MD

President of the Koto Hospital

Tokyo (Japan)

masatoshi.makuuchi@gmail.com 
Fig. 1. Number of top-cited publications by

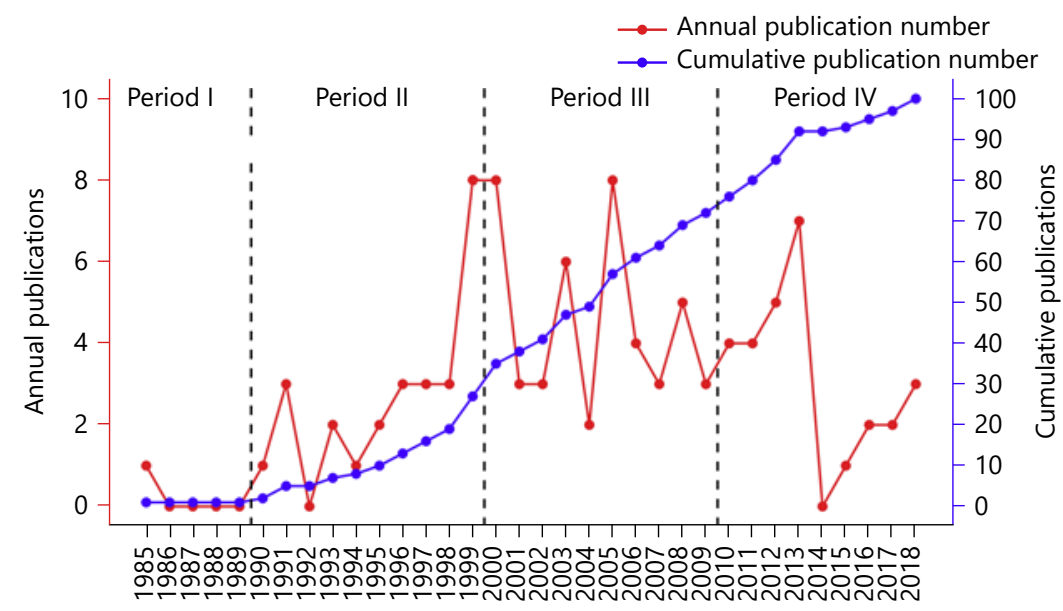
year.

carcinoma (HCC) is a major histological subtype of liver cancer, accounting for $70-85 \%$ of all cases, globally [2]. After many years of advancement, the treatment of HCC has gone from the first hepatectomy in Italy in 1886 (the patient died from major bleeding $6 \mathrm{~h}$ after the surgery) to safe, precise, and minimally invasive hepatectomy with a variety of other local therapies and systemic therapies under development [3]. The summary and evaluation of the evolution of HCC treatment over the past 40 years is difficult to chronicle. On the one hand, chapters in textbooks and umbrella reviews from time to time in the literature fail to provide a comprehensive overview of the incremental improvement. For example, some new technologies reported in the articles may have been very popular for a short period of time, only to disappear from practice shortly thereafter. In contrast, some clinical practices have been defined as lasting better alternatives leading to long-standing improvement in patient care.

Bibliometric citation analysis, a broadly used method to map the literature, might provide insight into temporal trends in the treatment of HCC. The citation numbers of an article indicate the importance of the study and reflect a direct influence on the understanding and treatment of diseases [4]. In this study, we analyzed the 100 most cited articles in the field of HCC treatment over the past 4 decades using bibliometric citation analysis to outline the evolution in HCC treatment. In turn, the data provide clinicians and researchers a general understanding of the evolution, as well as meaningful insight into future directions relative to advances in HCC management.

\section{Materials and Methods}

\section{Literature Search and Screening}

The Clarivate Analytics Web of Science Core Collection database was systematically searched from 1 January 1980 to November 2020. A summary of key words and the search strategy is shown in online suppl. Table 1 (for all online suppl. material, see www. karger.com/doi/10.1159/000513412). Only original articles and reviews with full manuscripts that focused on the treatment of HCC patients as the main topic were included. Literature reviews that briefly summarized published studies were excluded; editorials, consensus statements, and guidelines were also excluded to limit selection of articles to only those with high scientific merit in the field. Two reviewers (G.X. and B.J.) independently identified the top 100 papers according to the total citations (TC) of the papers, and any disagreement between the 2 reviewers was resolved by consensus involving a third reviewer (X.M.X.).

\section{Data Analyses and Visualization}

After identifying the 100 most frequently cited articles, we downloaded the 100 records including all available information from the Web of Science Core Collection database. The bibliographic information of the selected publications was converted and analyzed automatically by using the bibliometric package (Version 3.0.0) in R software (Version 3.6.1), as reported previously [5]. The information was extracted and analyzed using the bibliometric package including title, authors, institutions, countries or regions, number of TC, year of publication, journal, and impact factor. The main topic, sub topic, and article type of each article were also determined by reading the title, abstract, and full text, if necessary.

All of the information and data for each article were inserted into a spreadsheet and manipulated using Microsoft Excel 2019 (Microsoft Corp., Redmond, WA, USA). We created the graphs and figures using R software (Version 3.6.1) and EChart.js package (Version 4.5.0; https://echarts.apache.org/en/index.html), which is based on JavaScript. 


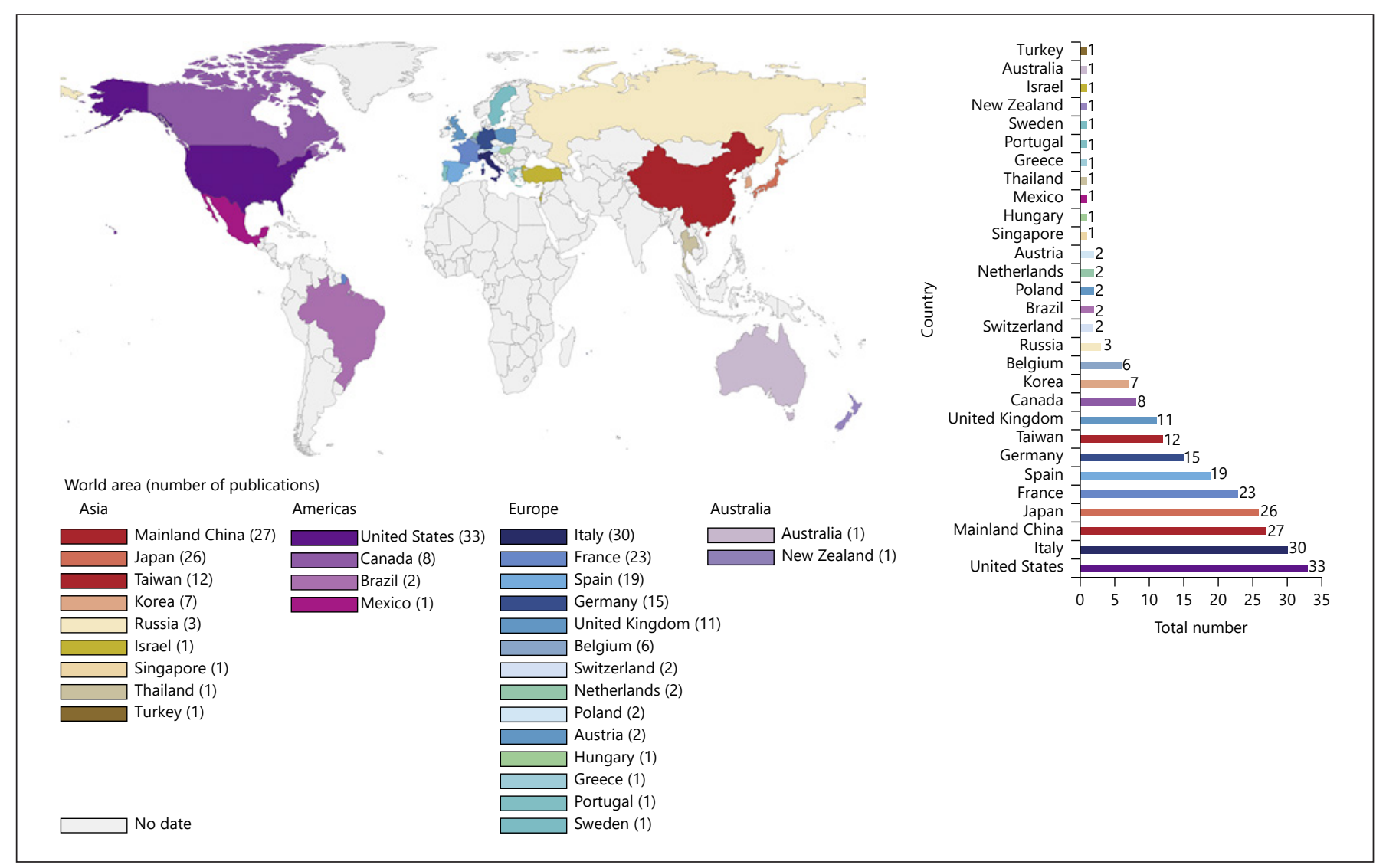

Fig. 2. Number of top-cited publications by country or region.

Table 1. Top 10 institutions with the most publications

\begin{tabular}{lcrr}
\hline Institutions & Publication & TC & TC/publication \\
\hline The University of Hong Kong & 11 & 7,581 & 689.18 \\
The University of Tokyo & 10 & 6,194 & 619.40 \\
The University of Barcelona & 9 & 9,577 & $1,064.11$ \\
The National Taiwan University Hospital & 9 & 8,499 & 944.33 \\
The University of Bologna & 7 & 11,215 & $1,602.14$ \\
The Chinese University of Hong Kong & 6 & 3,892 & 648.67 \\
The Fudan University & 4 & 5,027 & $1,256.75$ \\
The Kindai University & 4 & 3,357 & 839.25 \\
The Memorial Sloan-Kettering Cancer Center & 4 & 2,831 & 707.75 \\
The Chang Gung University & 4 & 1,750 & 437.50 \\
\hline
\end{tabular}

TC, total citation.

\section{Results}

\section{Citation Count and Publication Period}

A total of 202,966 articles focusing on the treatment of HCC were identified from the Web of Science Core Collection database from January 1980 to November 2020.
The 100 most influential articles are listed in online suppl. Table 2 in descending order according to the article's TC number. The number of citations varied from each paper and ranged from 7,243 ("Sorafenib in advanced hepatocellular carcinoma") to 341 ("Prospective evaluation of Pringle maneuver in hepatectomy for liver tumors by a 


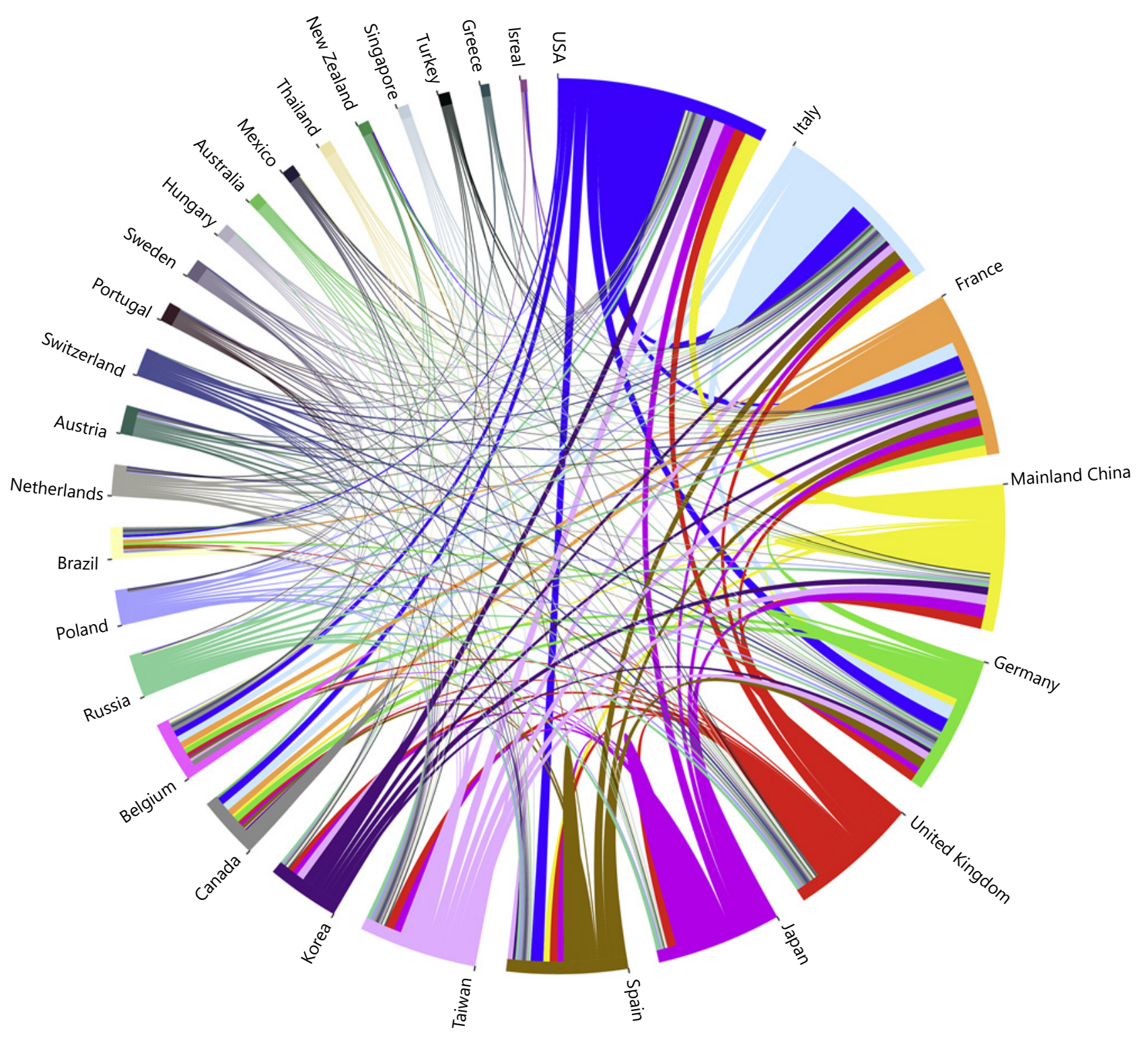

Fig. 3. The cooperation relationships of countries or regions that published the top 100 articles.

randomized study"). The earliest article in the list, which focused on the prognosis of HCC, was published in 1985. The most recent articles were 3 articles published in 2018 that focused on the systemic therapy of HCC; 2 articles were related to molecular targeted therapy and one was about immunotherapy. As noted in Figure 1, the year that yielded the highest number of influential articles was 1999 and $2000(n=8)$. Most included articles were published in the 2000s $(n=45)$, followed by the 2010s $(n=$
$28), 1990$ s $(n=26)$, and 1980s ( $n=1)$. Interestingly, only one of the most influential articles was published before 1990.

\section{Countries or Regions, Institutions, and Authors}

In analyzing countries (or regions) and institutions of the authors, the 100 most cited articles were originated from 29 countries or regions (shown in Fig. 2). Nine countries and regions contributed $>10$ articles, and 11 


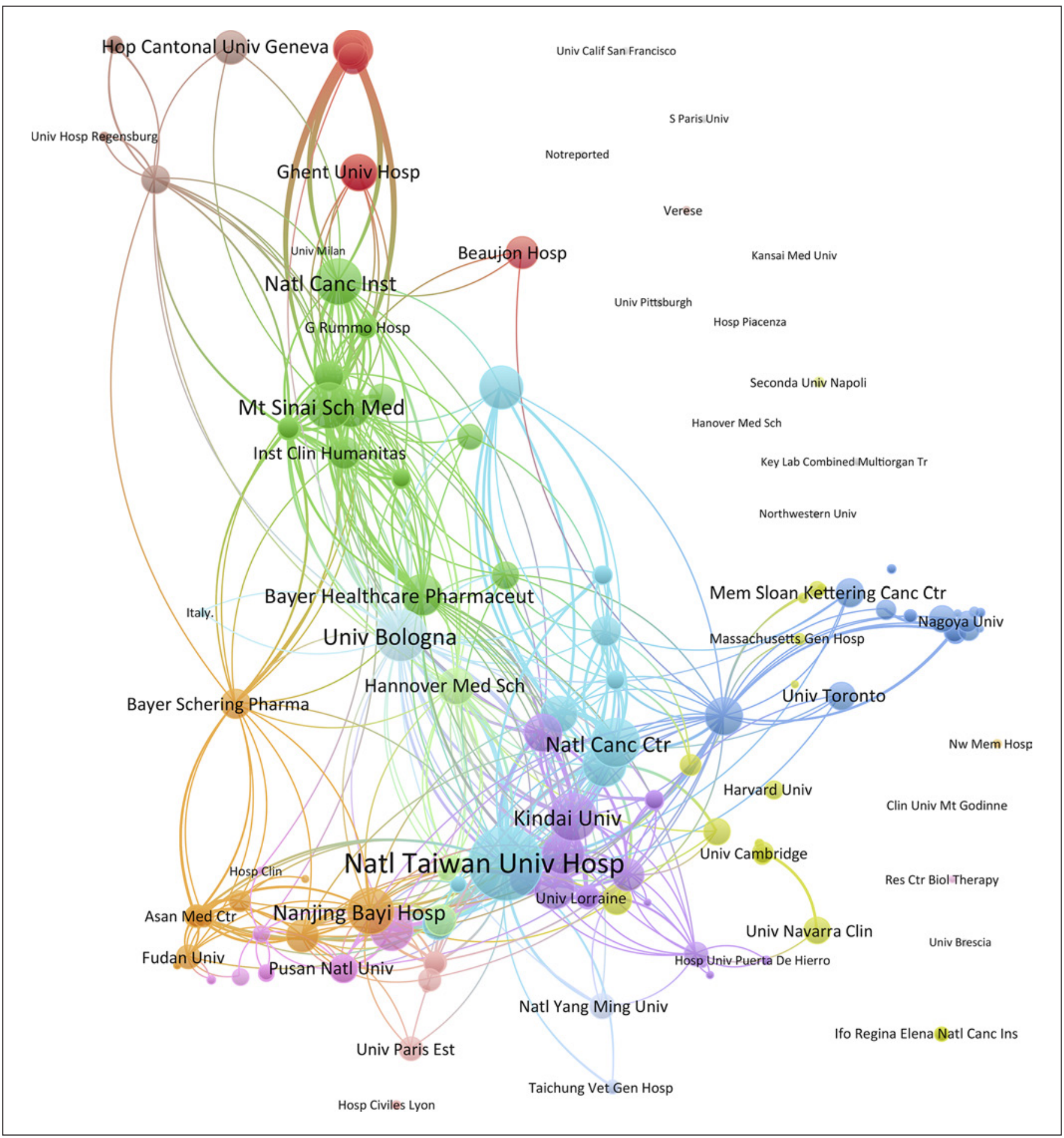

Fig. 4. The cooperation relationships of institutions that published the top 100 articles. 


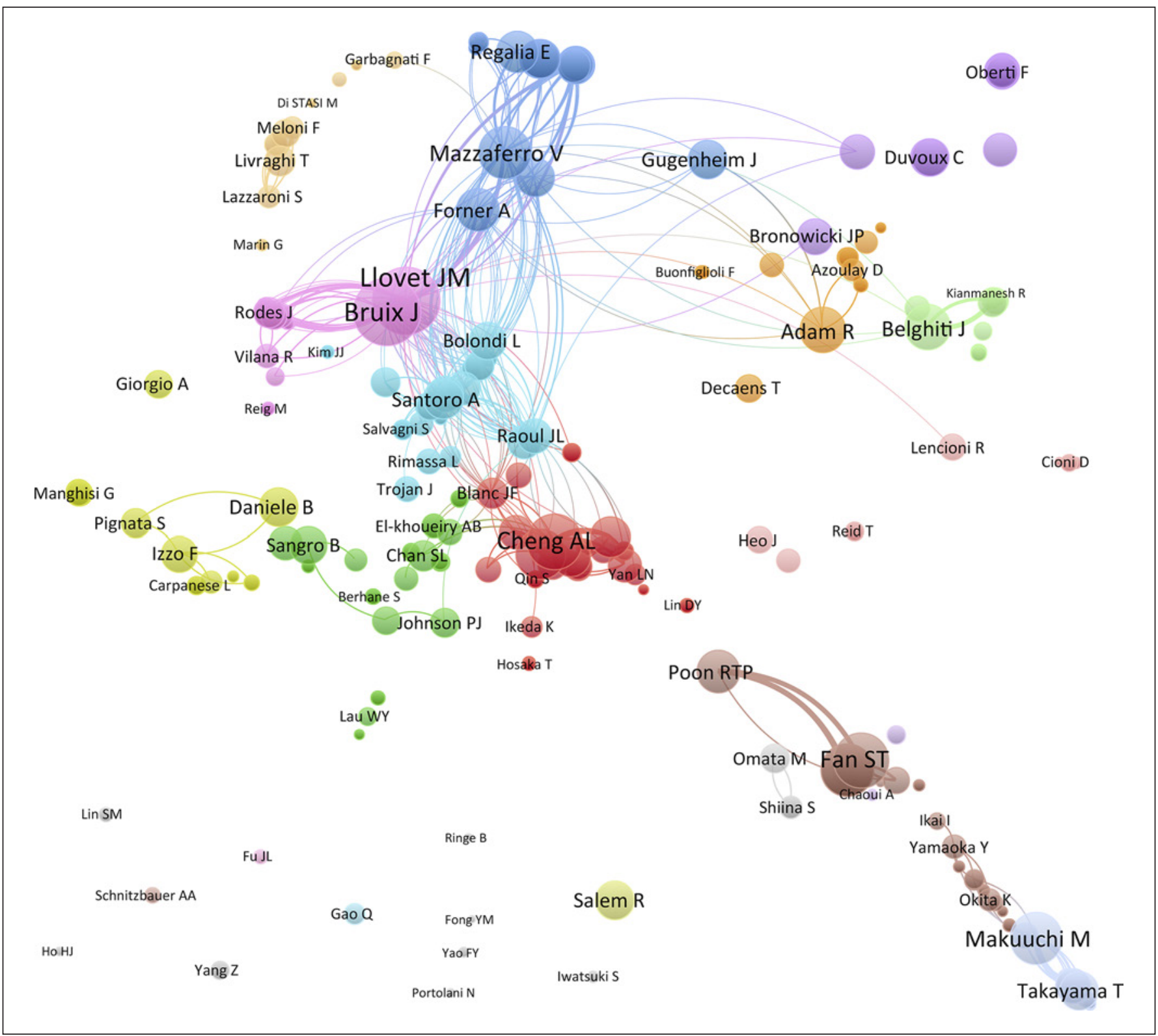

Fig. 5. The cooperation relationships of authors that published the top 100 articles.

countries contributed 1 article (shown in online suppl. Table 3). Among the 100 most influential articles, the USA contributed the most articles $(n=33)$, followed by Italy $(n=30)$, mainland China $(n=27)$, Japan $(n=26)$, France $(n=23)$, Spain $(n=19)$, Germany $(n=15)$, Taiwan $(n=12)$, and United Kingdom $(n=11)$. Figure 3 depicts the partnership among countries that published the 100 most influential articles, which demonstrated close cooperation among the various countries and regions.
As noted in Table 1, the top 10 institutions that published the most articles in the top 100 included the University of Hong Kong, the University of Tokyo, and the University of Barcelona with 11, 10, and 9 papers, respectively, with 7,581 citations, 6,194 citations, and 9,577 citations, respectively. The ratio of TC to publications reflects the TC numbers of each article. The University of Bologna has the highest ratio of TC $(1,602.14)$, followed by the Fudan University $(1,256.75)$ and the University of 
Table 2. Top 10 journals with the most publications

\begin{tabular}{llrrr}
\hline Journal & Publication & \multicolumn{1}{l}{ IF } & \multicolumn{1}{l}{ TC } & TC/publication \\
\hline Annals of Surgery & 23 & 9.476 & 12,525 & 544.57 \\
Hepatology & 14 & 14.971 & 10,404 & 743.14 \\
Gastroenterology & 9 & 19.809 & 4,525 & 502.78 \\
Journal of Clinical Oncology & 6 & 28.349 & 3,480 & 580.00 \\
Journal of Hepatology & 6 & 18.946 & 3,403 & 567.17 \\
Radiology & 6 & 7.608 & 4,799 & 799.83 \\
The Lancet & 5 & 59.102 & 5,907 & $1,181.40$ \\
Cancer & 4 & 6.102 & 3,158 & 789.50 \\
The Lancet Oncology & 4 & 35.386 & 5,194 & $1,298.50$ \\
New England Journal of Medicine & 4 & 70.67 & 12,884 & $3,221.00$
\end{tabular}

IF, impact factor; TC, total citation.

Barcelona $(1,064.11)$ (shown in Table 1). The cooperation among different countries, institutions, and authors is a critical driving force to promote the development of most successful large-scale trials. To this point, there seemed to be close cooperation among different institutions from various countries and regions (Fig. 3, 4). Moreover, authors were classified into $>10$ clusters in the authors' collaboration network analysis; several major research teams were identified, mainly including Llovet J.M., Bruix J., Mazzaferro V., Cheng A.L., Belghiti J., Adam R., Poon R.T.P., Fan S.T., and Makuuchi M. (shown in Fig. 5).

\section{Journals, Topics, and Article Types}

The top 100 influential articles were published in 27 journals. According to the number of the most influential articles published, the top 10 journals are listed in Table 2 . The Annals of Surgery published the most top 100 articles with 23 papers. The New England Journal of Medicine generated the largest quantity of TC with 12,884 citations. There were 3 journals with the ratio of TC to publications exceeding 1,000, namely, the New England Journal of Medicine (TC/publications 3,221.00), The Lancet Oncology (TC/publications 1,298.50), and The Lancet (TC/publications 1,181.40).

The main topic, subtopic, and article type of the 100 most influential articles were defined, and the relationships among the various topics and subtopics were established (shown in Fig. 6). Locoregional treatment was the most studied main topic $(n=31)$, followed by surgical management $(n=30)$, systemic therapy $(n=21)$, and outcome prediction $(n=18)$. Liver resection was the most studied subtopic $(n=21)$, followed by ablation $(n=18)$, clinicopathologic characteristics $(n=12)$, molecular tar-

Evolutions in the Management of

Hepatocellular Carcinoma geted therapy $(n=10)$, and liver transplantation $(n=9)$. Among the top 100 influential publications, there were 49 retrospective cohort studies, 31 prospective database studies, and 17 clinical trials (including 9 phase III trials, 5 phase II trials, 2 phase I/II trials, and 1 phase I trial). In addition, 3 reviews were also included as top 100 articles because the new criteria proposed in these reviews had a profound impact on HCC management. The most frequently cited articles that focused on surgical management appeared in the 1980s and decreased after 2010. The most frequently cited articles that focused on locoregional treatment and outcome prediction appeared in the 1990 s, peaked in the 2000s, and gradually declined over the past 10 years. Articles focusing on systemic therapy demonstrated an increasing trend over the last years examined (shown in Fig. 7).

\section{Discussion}

It is a challenging task to review the development and evolution of HCC treatment in the past 4 decades. In particular, there can be shortcomings in the information included in textbooks and the various published reviews, as these forms of information often are one sided, biased, or lack a systematic approach to identifying the most relevant data. The current study was important because we specifically summarized and analyzed the 100 most cited articles on the topic of HCC over the last 4 decades. Of note, most articles enrolled in the list were derivatives of cooperative research among different institutions from various countries or regions around the world. Most papers that were cited in the top 100 focused on surgical management or locoregional treatment rather than sys- 


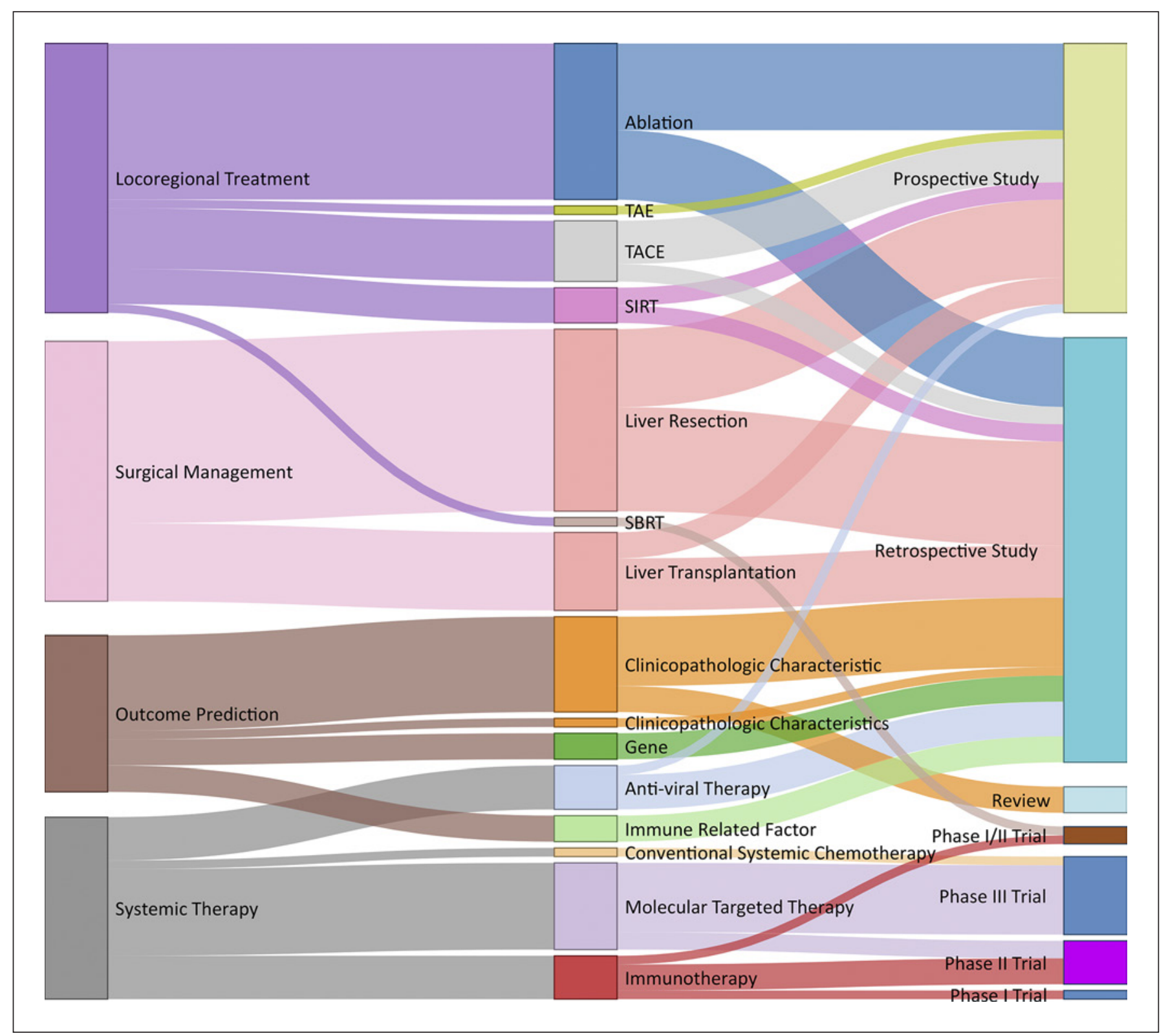

Fig. 6. Article types and topics of the 100 most influential publications. TACE, transarterial chemoembolization; SIRT, selective internal radiation therapy; SBRT, stereotactic body radiation therapy.

tematic treatment such as targeted drugs. A possible explanation was that targeted drugs are a relatively novel treatment, and articles on this topic have not had as much time to accumulate citations. Notably, among the top 100 influential publications, nearly one-half were retrospective in nature. Most likely, in the earlier years, some treatment strategies were first proposed in retrospective cohort studies and then subsequently demonstrated to be effective and feasible in prospective studies and RCT studies. Among the 100 most influential articles, USA, East Asian countries, and European countries including Italy, Spain, and France contributed the majority of the articles. This finding was not surprising given the advanced science and technology capacities in the USA and Europe, as well as the higher regional incidence of HCC in Asia. In examining journal types, the Annals of Surgery published the largest number of top-cited articles on HCC treatment, suggesting the treatment of HCC re- 
Fig. 7. Trends in top-cited publications by different main topics over time.

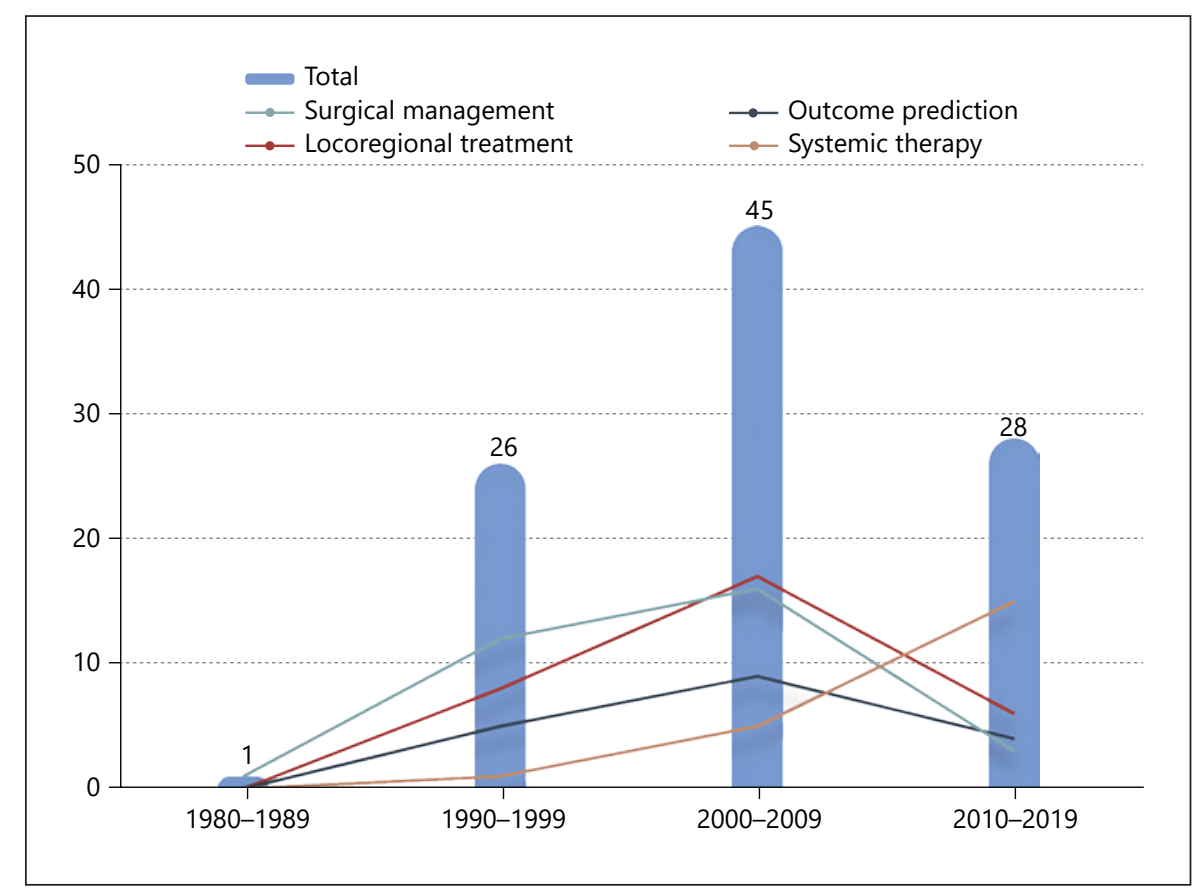

mains a popular surgical topic. That said, over the last 2 decades, the number of top-cited papers on the topics of locoregional therapy and systemic therapy did rise considerably. The reason for this trend was likely due to the evolution of molecular pathway targeted therapy and a better understanding of molecular biology of liver carcinogenesis, which induced a treatment shift in HCC towards personalized therapy and immunotherapy.

Surgeries including hepatectomy and liver transplantation are the most preferred options for HCC treatment [6-8]. Among the 100 most cited articles, improvement and optimization of HCC surgery accounted for onethird of all studies. In examining the content of the topcited liver surgery papers, the data suggested that the optimization of HCC surgery mainly took place from the 1980 s to the early 21 st century. Over this time, liver resection for larger tumors in more difficult tumor locations with a more precise understanding of intraparenchymal dissection and intrahepatic anatomy reached a state-ofthe-art level. The perioperative assessment and safety of hepatectomy was also dramatically improved. Specifically, mortality following major hepatectomy was reduced to $<5 \%$, with death after minor hepatectomy reduced to $<1 \%$. During this same time period, the overall 5 -year survival among patients with HCC increased to $>50 \%$ [9]. Interestingly, over the last 10 years, the number of studies related to the open liver resection technique has gradually plateaued. In contrast, data on minimally invasive liver resection techniques have markedly increased. These data could suggest that the minimally invasive approach is becoming more common relative to conventional open liver resection for the treatment of HCC. The emergence of minimally invasive laparoscopic, robotic surgery, and local ablation technology enables diverse treatment strategies for patients with early-stage HCC. As such, articles on these related fields are likely to attract more attention in the future.

Preoperative risk assessment of liver surgery was another common topic among the top 100 cited papers. For example, an article from Japan retrospectively analyzed $>500$ HCC patients treated in the National Cancer Center Hospital in Tokyo during the 1990s. In this article, the authors proposed the "Makuuchi criteria" which involve establishing standards for liver resection based on indocyanine green clearance rate, bilirubin level, and ascites, providing a comprehensive preoperative evaluation for hepatectomy and selection of surgical strategy [10]. This manuscript was the earliest highly cited research that was published in the preoperative assessment field. Following this seminal article, authors from Japan and USA published 2 additional influential articles in the field of risk assessment in 1997 and 2000, respectively [11, 12]. In addition, in 1997, a study developed by researchers from the Hospital Clinic i Provincial in Spain first proposed that preoperative portal hypertension $(\mathrm{PH})$ was a contraindication to hepatectomy [13]. More recently, the same 
group of investigators proposed the Barcelona Clinic Liver Cancer (BCLC) staging schema that listed $\mathrm{PH}$, as well as multiple HCC, as contraindications for hepatectomy of HCC [14]. In 2008, however, a paper from Japan [15] revealed that hepatectomy could actually benefit patients who had multiple HCC or HCC with PH and proposed expansion of the indications for hepatectomy beyond the BCLC recommendations, which has subsequently been widely accepted today. Despite these data, the guidelines of the European Association for the Study of the Liver (EASL) and the American Association for the Study of Liver Disease (AASLD) still recommend the BCLC staging, which limited the indications of hepatectomy to early-stage patients with solitary HCC $[7,8]$. Of note, in much of Asia, while the BCLC staging is considered important as a reference, most treatment plans for HCC tend to emphasize a more aggressive role for surgical resection [16]. RCTs with large sample are required, however, to provide further validation.

Surgical liver parenchymal dissection technique has similarly evolved from the 1960s, which largely focused on the "finger fracture" technique [17], into more precise surgical approaches including the Cavitron Ultrasonic Surgical Aspirator, Harmonic ultrasonic knife, LigaSure, and Endo-GIA Stapler [18]. Meanwhile, the broad application of ultrasound during the operation has made more precise liver parenchymal dissection possible [19]. In addition, the Pringle maneuver, which involves intermittent or continuous inflow occlusion, as well as low central venous pressure, has been widely used to improve the safety of liver surgery [20-22]. Furthermore, in 2008, beyond variations in parenchymal techniques, a study reported that anatomical hepatectomy for single nodular HCC may provide a better prognosis [23]. To date, in clinical practice, due to limitations related to liver function and tumor location, nonanatomical parenchymal saving hepatectomy still accounts for the large proportion of liver surgery today. In fact, anatomic hepatectomy among patients with poorly functioning livers may increase postoperative morbidity and mortality.

With the evolution of HCC surgical management, methods to improve the tolerance of HCC patients with an insufficient residual liver function have remained a major concern. In 1986, the portal vein embolization was proposed to increase residual liver volume in order to expand surgical indications for hepatectomy of HCC [24]. In 2003, a research revealed that portal vein embolization could significantly reduce the incidence of postoperative complications among patients undergoing liver resection for HCC with chronic underlying liver disease [25]. Al- most a decade later in 2012, another surgical strategy was proposed to increase the residual liver volume - associating liver partition and portal vein ligation for staged hepatectomy (ALPPS) [26]. This technique has been gradually adopted in clinical practice, yet the widespread use of ALPPS has been somewhat limited due to the associated high postoperative morbidity and mortality [27, 28].

More recently, reports in the literature have increasingly focused on minimally invasive liver surgery. After the laparoscopic hepatectomy was first reported in 1991 [29], the use of laparoscopic liver resection has grown dramatically over the last 20 years. Two International Congresses on Laparoscopic Hepatectomy were held in 2008 and 2015 that defined the indications of laparoscopic hepatectomy for liver cancer, which essentially mirrored the indications and scope as open hepatectomy [30, 31]. In addition, robotic hepatectomy has recently also become more prominent in the field of liver surgery as a new minimally invasive surgical technique. Interestingly, while minimally invasive techniques largely originated in Europe and USA, the application of this approach has expanded the most in Asian countries as indicated by the published literature [32]. It is consistent with the fact that Asia has the largest number of patients with HCC. While significant progress had been made in the field of minimally invasive hepatectomy over the past 3 decades, only 1 article was among the 100 most influential articles. This finding was most likely due to the certainty about the long-term effects of laparoscopic hepatectomy for HCC [32]. Even though few RCTs are available at present, more data on oncological, cost-effective, and technical aspects of HCC care are emerging.

Another breakthrough in the surgical management of HCC was liver transplantation. In 1967, the liver transplantation was successfully performed for the first time on a 19-month-old patient with HCC, who lived for 13 months, subsequently dying from tumor metastasis [33]. Since then, liver transplantation has developed rapidly and has been widely adopted as a main treatment option for patients with HCC. To this point, 24 years ago, a research group from Italy proposed the Milan criteria [34]. This seminal article was published in 1996 and is noteworthy for being the most cited paper in the field of HCC, laying the foundation for liver transplantation as the standard of care for HCC. With time, investigators began to consider that the Milan criteria might be too conservative, and some researchers proposed the expanded UCSF criteria and the Up-to-7 criteria in 2001 and 2009, respectively $[35,36]$. These 2 highly cited articles advocated for expanded indications for liver transplantation in order to 
maximize the benefit of this therapy for patients with HCC on the waiting list. In addition, to address the problem of donor organ shortage, the split liver transplantation and living donor liver transplantation were proposed in 1988 and 1990, respectively $[37,38]$. At that time, although some Asian countries allowed the use of organs from brain-dead patients, these techniques were not widely accepted due to some regional or cultural reasons. Instead, living donor liver transplantation was the more commonly used treatment of HCC in Asia compared with other parts of the world [39]. Currently, liver transplantation for patients with HCC has accounted for 15$50 \%$ of the total number of liver transplantations in most medical centers in the world [40-42].

In addition to liver resection and liver transplantation, locoregional therapy for HCC rapidly increased in the 1980-1990s including various ablation, transarterial chemoembolization, selective internal radiation therapy (SIRT) (also named transarterial radioembolization), and stereotactic body radiation therapy techniques. Most of these therapies have been treatment options for early stage of HCC, unresectable HCC, or downstaging and bridging prior to liver transplantation [43]. In 1994, a study from Japan reported that totally 18 patients with a single small HCC were successfully treated using firstgeneration microwave coagulation therapy guided by ultrasound (the first highly cited article on locoregional therapy of HCC) [44]. Since then, reports on ablations that have been reported and cited the most over the past 30 years have mainly focused on the effect of radiofrequency ablation (RFA) and percutaneous ethanol injection to treat HCC. At present, the EASL and AASLD guidelines recommend using locoregional ablation for patients with single $\mathrm{HCC}<2 \mathrm{~cm}$ and single or $2-3$ nodules $<3 \mathrm{~cm}$ among individuals who are unable to undergo surgery or liver transplantation $[7,8]$. In 1999, researchers compared the efficacy of RFA versus percutaneous ethanol injection to treat small HCC and demonstrated that RFA was more effective [45]. This article became the most cited article in the field of locoregional ablative treatment of HCC. The conclusion from this article was also verified by 4 subsequent RCTs, which were also in the top 100 cited articles [46-49]. For patients with $\mathrm{HCC}<5 \mathrm{~cm}$ combined with cirrhosis, the incidence of severe complications after RFA treatment was only $1-5 \%$, and the mortality was $<0.3 \%$ [50]. Laser ablation, irreversible electroporation, and cryoablation were not included in studies among the top 100 list, likely because these are more recent treatment approaches. A similar "90s peak" was demonstrated in the field of locoregional therapy for

Evolutions in the Management of

Hepatocellular Carcinoma
HCC and may be in part be a result of older work related to established therapeutic strategies that are no longer cited, as well as newer therapeutic techniques having insufficient time to accumulate citations.

In 2007, the Radioembolization Brachytherapy Oncology Consortium held a conference in the USA and formulated a consensus statement regarding SIRT with yttrium-90 for HCC [51]. Subsequently, 4 highly cited articles confirmed the efficacy and safety of SIRT to treat advanced HCC [52-55]. Two more recently published articles involved SARAH and SIReNevib controlled studies comparing SIRT and sorafenib [7,8]. Although SIRT did not have better efficacy than sorafenib for unresectable HCC, it was better tolerated than sorafenib $[56,57]$. Due to the paucity of high-level evidence, the EASL and AASLD still do not recommend SIRT as a preferred treatment of HCC $[7,8]$. This may be a possible reason why only 4 articles related to SIRT were included in the 100 most cited articles. The effect of SIRT on HCC needs to be verified further in large RCTs. The dominance of articles about systemic therapy especially in recent time may reflect shifts in research interests within the scientific community over time. Historically, both surgery and locoregional treatment received much attention and were established early as effective therapies for HCC. While interest may have shifted away from evaluating therapeutic strategies, the survival benefits of these treatment options still remain an important question for patients with advanced HCC. Before 2007, there was no systemic therapy that was recommended in the guidelines of HCC treatment as this tumor is notoriously chemoresistant. Sorafenib was the first promising systemic therapy drug for advanced HCC $[58,59]$. In 2008, the results of SHARP, published by the SHARP Investigators Study Group in the New England Journal of Medicine, demonstrated that sorafenib prolonged survival among patients with advanced HCC by 2.8 months compared with placebo [59]. This article thus gained scientific interest in recent time and became the most highly cited article in the field of HCC treatment. Additionally, Dr. Lencioni and M. Llovet proposed modified RECIST (mRECIST) criteria, which provided a reliable means to assess tumor response in tumors treated with molecular therapies in HCC clinical trials [60]. Since then, mRECIST criteria have been used extensively in HCC clinical research and in major phase II-III trials of intermediate and advanced HCC. Indeed, mRECIST criteria indirectly promoted the development of clinical trials of different molecular therapeutics for advanced HCC. However, unfortunately, multiple other clinical trials of advanced HCC including brivanib, evero- 
limus, ramucirumab, tivantinib, and sunitinib failed to demonstrate superior or equivalent to sorafenib [61-65]. Although these studies ended in failure, high citation numbers indicated great scientific value in the field of HCC treatment, which reflected the enormous attention that clinicians and researchers have toward the treatment of advanced HCC. In turn, few reports on new therapy of advanced HCC occurred until December 2016, when the results of the RESORCE clinical trial were published in The Lancet [66]. Due to findings in this trial, regorafenib was approved as a second-line treatment drug for HCC in 2017 [66]. Subsequently, other phase III studies demonstrated beneficial results associated with first-line lenvatinib [67] and second-line cabozantinib [68] and ramucirumab [69]. In addition, based on data from single-arm phase II studies, the US Food and Drug Administration approved 2 PD-1 monoclonal antibodies (nivolumab and pembrolizumab) as second-line treatment of HCC through an accelerated approval mechanism [70, 71]. In recent years, researchers and clinicians have begun to focus on combination strategies to improve survival among patients with advanced HCC even further [72]. Compared with the benefits of surgery - when feasible - targeted therapy and immunotherapy may be much less cost effective and associated with lower actual 5-year survival. However, it must be recognized that their appearance brings more treatment options and survival benefits for patients with advanced HCC.

While the top 100 articles identified in the present study represented highly influential work in HCC management, the current study may not have captured all important articles in this field. In particular, recent articles that did not have sufficient time to accumulate citations and older articles in which early citations may not be reliably indexed in modern databases would likely not have been reflected in our analysis. It is also possible that our search terms may have missed articles relevant to HCC management, although we did use broad terms in order to reduce this possibility.

Overall, based on bibliometric citation analysis of the literature over the last 40 years, the 100 most influential articles related to the landscape of HCC treatment were identified to provide useful insights. Moreover, the present study also provided a comprehensive and quantitative analysis of the most historically significant HCC management articles, acknowledging the key contributions made to the evolution and advancement of this specialized field. Our findings demonstrated that there is currently significant interest among clinicians and researchers to develop nonsurgical therapies in the treatment of HCC. There re- mains a need, however, to identify effective combinations of modern innovative surgical technology with more effective systemic therapies to improve outcomes of patients with HCC. Undoubtedly, research, discovery, and innovation in the area of HCC management will continue to evolve and be an area of continued growth and interest in the future.

\section{Statement of Ethics}

This study is a bibliometric analysis of the articles related to management of hepatocellular carcinoma, and the data were obtained from the Clarivate Analytics Web of Science Core Collection database, so ethical approval and consent to participate were not necessary for this paper.

\section{Conflict of Interest Statement}

The authors declare no potential conflicts of interest.

\section{Funding Sources}

No source of funding.

\section{Author Contributions}

S.D. Du, M. Makuuchi, T.M. Pawlik, and Y.L. Mao: study concept and design. G. Xu, B. Jin and X.M. Xian: acquisition of data. H.Y. Yang and H.T. Zhao: analysis and interpretation of data. G. $\mathrm{Xu}$ and B. Jin: drafting of the manuscript. S.D. Du, M. Makuuchi, T.M. Pawlik, and Y.L. Mao: critical revision of the manuscript for important intellectual content.

References

1 Bray F, Ferlay J, Soerjomataram I, Siegel RL, Torre LA, Jemal A. Global cancer statistics 2018: GLOBOCAN estimates of incidence and mortality worldwide for 36 cancers in 185 countries. CA Cancer J Clin. 2018 Nov;68(6): 394-424.

2 Torre LA, Bray F, Siegel RL, Ferlay J, LortetTieulent J, Jemal A. Global cancer statistics, 2012. CA Cancer J Clin. 2015 Mar;65(2):87108.

3 Lius A. Di un adenoma del fegato. Centralblatt Fur Chir. 1887/1886;5:99.

4 Brooke BS, Nathan H, Pawlik TM. Trends in the quality of highly cited surgical research over the past 20 years. Ann Surg. 2009 Jan; 249(1):162-7.

5 Aria M, Cuccurullo C. Bibliometrix: an R-tool for comprehensive science mapping analysis. J Informetr. 2017 Nov 1;11(4):959-75. 
6 Liver Cancer Study Group of Japan. Primary liver cancer in Japan. Clinicopathologic features and results of surgical treatment. Ann Surg. 1990 Mar;211(3):277-87.

7 EASL Clinical Practice Guidelines. EASL Clinical Practice Guidelines: management of hepatocellular carcinoma. J Hepatol. 2018 Jul; 69(1):182-236

8 Heimbach JK, Kulik LM, Finn RS, Sirlin CB, Abecassis MM, Roberts LR, et al. AASLD guidelines for the treatment of hepatocellular carcinoma. Hepatology. 2018 Jan;67(1):35880.

9 Fan ST, Mau Lo C, Poon RT, Yeung C, Leung Liu C, Yuen WK, et al. Continuous improvement of survival outcomes of resection of hepatocellular carcinoma: a 20-year experience. Ann Surg. 2011 Apr;253(4):745-58.

10 Makuuchi M, Kosuge T, Takayama T, Yamazaki S, Kakazu T, Miyagawa S, et al. Surgery for small liver cancers. Semin Surg Oncol. 1993 Jul-Aug;9(4):298-304.

11 Kubota K, Makuuchi M, Kusaka K, Kobayashi T, Miki K, Hasegawa K, et al. Measurement of liver volume and hepatic functional reserve as a guide to decision-making in resectional surgery for hepatic tumors. Hepatology. 1997 Nov;26(5):1176-81.

12 Vauthey JN, Chaoui A, Do KA, Bilimoria MM, Fenstermacher MJ, Charnsangavej C, et al. Standardized measurement of the future liver remnant prior to extended liver resection: methodology and clinical associations. Surgery. 2000 May;127(5):512-9.

13 Bruix J, Castells A, Bosch J, Feu F, Fuster J, Garcia-Pagan JC, et al. Surgical resection of hepatocellular carcinoma in cirrhotic patients: prognostic value of preoperative portal pressure. Gastroenterology. 1996 Oct;111(4): 1018-22.

14 Llovet JM, Brú C, Bruix J. Prognosis of hepatocellular carcinoma: the BCLC staging classification. Semin Liver Dis. 1999;19(3):32938.

15 Ishizawa T, Hasegawa K, Aoki T, Takahashi M, Inoue Y, Sano K, et al. Neither multiple tumors nor portal hypertension are surgical contraindications for hepatocellular carcinoma. Gastroenterology. 2008 Jun;134(7):190816.

16 Omata M, Cheng AL, Kokudo N, Kudo M, Lee JM, Jia J, et al. Asia-Pacific clinical practice guidelines on the management of hepatocellular carcinoma: a 2017 update. Hepatol Int. 2017 Jul;11(4):317-70.

17 Lin TY, Chen KM, Liu TK. Total right hepatic lobectomy for primary hepatoma. Surgery. 1960 Dec;48:1048-60.

18 Wong TC, Lo CM. Resection strategies for hepatocellular carcinoma. Semin Liver Dis. 2013 Aug;33(3):273-81.

19 Takayama T, Makuuchi M. Intraoperative ultrasonography and other techniques for segmental resections. Surg Oncol Clin N Am. 1996 Apr;5(2):261-9.
20 Man K, Fan ST, Ng IO, Lo CM, Liu CL, Wong J. Prospective evaluation of Pringle maneuver in hepatectomy for liver tumors by a randomized study. Ann Surg. 1997 Dec;226(6):704-3.

21 Melendez JA, Arslan V, Fischer ME, Wuest D, Jarnagin WR, Fong Y, et al. Perioperative outcomes of major hepatic resections under low central venous pressure anesthesia: blood loss, blood transfusion, and the risk of postoperative renal dysfunction. J Am Coll Surg. 1998 Dec;187(6):620-5.

22 Belghiti J, Noun R, Malafosse R, Jagot P, Sauvanet $\mathrm{A}$, Pierangeli $\mathrm{F}$, et al. Continuous versus intermittent portal triad clamping for liver resection: a controlled study. Ann Surg. 1999 Mar;229(3):369-75.

23 Hasegawa K, Kokudo N, Imamura H, Matsuyama Y, Aoki T, Minagawa M, et al. Prognostic impact of anatomic resection for hepatocellular carcinoma. Ann Surg. 2005 Aug; 242(2):252-9.

24 Kinoshita H, Sakai K, Hirohashi K, Igawa S, Yamasaki O, Kubo S. Preoperative portal vein embolization for hepatocellular carcinoma. World J Surg. 1986 Oct;10(5):803-8.

25 Farges O, Belghiti J, Kianmanesh R, Regimbeau JM, Santoro R, Vilgrain V, et al. Portal vein embolization before right hepatectomy: prospective clinical trial. Ann Surg. 2003 Feb; 237(2):208-17.

26 Schnitzbauer AA, Lang SA, Goessmann H, Nadalin S, Baumgart J, Farkas SA, et al. Right portal vein ligation combined with in situ splitting induces rapid left lateral liver lobe hypertrophy enabling 2 -staged extended right hepatic resection in small-for-size settings. Ann Surg. 2012 Mar;255(3):405-14.

27 Wang Z, Peng Y, Hu J, Wang X, Sun H, Sun $J$, et al. Associating liver partition and portal vein ligation for staged hepatectomy for unresectable hepatitis B virus-related hepatocellular carcinoma: a single center study of $45 \mathrm{pa}-$ tients. Ann Surg. 2020 Mar;271(3):534-41.

28 Alvarez FA, Ardiles V, de Santibañes M, Pekolj J, de Santibañes E. Associating liver partition and portal vein ligation for staged hepatectomy offers high oncological feasibility with adequate patient safety: a prospective study at a single center. Ann Surg. 2015 Apr; 261(4):723-32.

29 Reich H, McGlynn F, DeCaprio J, Budin R. Laparoscopic excision of benign liver lesions. Obstet Gynecol. 1991 Nov;78(5 Pt 2):956-8.

30 Buell JF, Cherqui D, Geller DA, O'Rourke N, Iannitti D, Dagher I, et al. The international position on laparoscopic liver surgery: the Louisville statement, 2008. Ann Surg. 2009 Nov;250(5):825-30.

31 Wakabayashi G, Cherqui D, Geller DA, Buell JF, Kaneko H, Han HS, et al. Recommendations for laparoscopic liver resection: a report from the second international consensus conference held in Morioka. Ann Surg. 2015 Apr; 261(4):619-29.
32 Cai X. Laparoscopic liver resection: the current status and the future. Hepatobiliary Surg Nutr. 2018 Apr;7(2):98-104.

33 Starzl TE, Groth CG, Brettschneider L, Penn I, Fulginiti VA, Moon JB, et al. Orthotopic homotransplantation of the human liver. Ann Surg. 1968 Sep;168(3):392-415.

34 Mazzaferro V, Regalia E, Doci R, Andreola S, Pulvirenti A, Bozzetti F, et al. Liver transplantation for the treatment of small hepatocellular carcinomas in patients with cirrhosis. N Engl J Med. 1996 Mar 14;334(11):693-9.

35 Yao FY, Ferrell L, Bass NM, Watson JJ, Bacchetti P, Venook A, et al. Liver transplantation for hepatocellular carcinoma: expansion of the tumor size limits does not adversely impact survival. Hepatology. 2001 Jun;33(6): 1394-403.

36 Mazzaferro V, Llovet JM, Miceli R, Bhoori S, Schiavo M, Mariani L, et al. Predicting survival after liver transplantation in patients with hepatocellular carcinoma beyond the Milan criteria: a retrospective, exploratory analysis. Lancet Oncol. 2009 Jan;10(1):35-43.

37 Pichlmayr R, Ringe B, Gubernatis G, Hauss J, Bunzendahl $\mathrm{H}$. Transplantation of a donor liver to 2 recipients (splitting transplantation): a new method in the further development of segmental liver transplantation. Langenbecks Arch Chir. 1988;373(2):127-30.

38 Strong RW, Lynch SV, Ong TH, Matsunami H, Koido Y, Balderson GA. Successful liver transplantation from a living donor to her son. N Engl J Med. 1990 May 24;322(21): $1505-7$

39 Hwang S, Lee SG, Belghiti J. Liver transplantation for HCC: its role: Eastern and Western perspectives. J Hepatobiliary Pancreat Sci. 2010 Jul;17(4):443-8.

40 de Villa V, Lo CM. Liver transplantation for hepatocellular carcinoma in Asia. Oncologist. 2007 Nov; 12(11):1321-31.

41 Kim WR, Lake JR, Smith JM, Skeans MA, Schladt DP, Edwards EB, et al. OPTN/SRTR 2013 Annual Data Report: liver. Am J Transplant. 2015 Jan;15(Suppl 2):1-28.

42 Adam R, Karam V, Delvart V, O'Grady J, Mirza D, Klempnauer J, et al. Evolution of indications and results of liver transplantation in Europe. A report from the European Liver Transplant Registry (ELTR). J Hepatol. 2012 Sep;57(3):675-88.

43 Breen DJ, Lencioni R. Image-guided ablation of primary liver and renal tumours. Nat Rev Clin Oncol. 2015 Mar;12(3):175-86.

44 Seki T, Wakabayashi M, Nakagawa T, Itho T, Shiro T, Kunieda K, et al. Ultrasonically guided percutaneous microwave coagulation therapy for small hepatocellular carcinoma. Cancer. 1994 Aug 1;74(3):817-25.

45 Livraghi T, Goldberg SN, Lazzaroni S, Meloni F, Solbiati L, Gazelle GS. Small hepatocellular carcinoma: treatment with radio-frequency ablation versus ethanol injection. Radiology. 1999 Mar;210(3):655-61.
Evolutions in the Management of

Hepatocellular Carcinoma
Liver Cancer 2021;10:137-150

DOI: $10.1159 / 000513412$ 
46 Lencioni RA, Allgaier HP, Cioni D, Olschewski M, Deibert P, Crocetti L, et al. Small hepatocellular carcinoma in cirrhosis: randomized comparison of radio-frequency thermal ablation versus percutaneous ethanol injection. Radiology. 2003 Jul;228(1):235-40.

47 Lin SM, Lin CJ, Lin CC, Hsu CW, Chen YC. Radiofrequency ablation improves prognosis compared with ethanol injection for hepatocellular carcinoma. Gastroenterology. 2004 Dec;127(6):1714-23.

48 Shiina S, Teratani T, Obi S, Sato S, Tateishi R, Fujishima T, et al. A randomized controlled trial of radiofrequency ablation with ethanol injection for small hepatocellular carcinoma. Gastroenterology. 2005 Jul;129(1):122-30.

49 Lin SM, Lin CJ, Lin CC, Hsu CW, Chen YC. Randomised controlled trial comparing percutaneous radiofrequency thermal ablation, percutaneous ethanol injection, and percutaneous acetic acid injection to treat hepatocellular carcinoma of $3 \mathrm{~cm}$ or less. Gut. 2005 Aug;54(8):1151-6.

50 Nault JC, Sutter O, Nahon P, Ganne-Carrié N, Séror O. Percutaneous treatment of hepatocellular carcinoma: state of the art and innovations. J Hepatol. 2018 Apr;68(4):783-97.

51 Kennedy A, Nag S, Salem R, Murthy R, McEwan AJ, Nutting C, et al. Recommendations for radioembolization of hepatic malignancies using yttrium-90 microsphere brachytherapy: a consensus panel report from the Radioembolization Brachytherapy Oncology Consortium. Int J Radiat Oncol Biol Phys. 2007 May 1;68(1):13-23.

52 Kulik LM, Carr BI, Mulcahy MF, Lewandowski RJ, Atassi B, Ryu RK, et al. Safety and efficacy of $90 \mathrm{Y}$ radiotherapy for hepatocellular carcinoma with and without portal vein thrombosis. Hepatology. 2008 Jan;47(1):7181.

53 Salem R, Lewandowski RJ, Mulcahy MF, Riaz A, Ryu RK, Ibrahim S, et al. Radioembolization for hepatocellular carcinoma using yttrium-90 microspheres: a comprehensive report of long-term outcomes. Gastroenterology. 2010 Jan;138(1):52-64.

54 Sangro B, Carpanese L, Cianni R, Golfieri R, Gasparini D, Ezziddin S, et al. Survival after yttrium-90 resin microsphere radioembolization of hepatocellular carcinoma across Barcelona Clinic Liver Cancer stages: a European evaluation. Hepatology. 2011 Sep 2;54(3): $868-78$.
55 Salem R, Lewandowski RJ, Kulik L, Wang E, Riaz A, Ryu RK, et al. Radioembolization results in longer time-to-progression and reduced toxicity compared with chemoembolization in patients with hepatocellular carcinoma. Gastroenterology. 2011 Feb;140(2): 497-e2.

56 Chow PKH, Gandhi M, Tan SB, Khin MW, Khasbazar A, Ong J, et al. SIRveNIB: selective internal radiation therapy versus sorafenib in Asia-Pacific patients with hepatocellular carcinoma. J Clin Oncol. 2018 Jul 1;36(19):191321.

57 Vilgrain V, Pereira H, Assenat E, Guiu B, Ilonca AD, Pageaux GP, et al. Efficacy and safety of selective internal radiotherapy with yttrium-90 resin microspheres compared with sorafenib in locally advanced and inoperable hepatocellular carcinoma (SARAH): an open-label randomised controlled phase 3 trial. Lancet Oncol. 2017 Dec;18(12):162436.

58 Cheng AL, Kang YK, Chen Z, Tsao CJ, Qin S, Kim JS, et al. Efficacy and safety of sorafenib in patients in the Asia-Pacific region with advanced hepatocellular carcinoma: a phase III randomised, double-blind, placebo-controlled trial. Lancet Oncol. 2009 Jan;10(1): 25-34.

59 Llovet JM, Ricci S, Mazzaferro V, Hilgard P, Gane E, Blanc JF, et al. Sorafenib in advanced hepatocellular carcinoma. N Engl J Med. 2008 Jul 24;359(4):378-90.

60 Lencioni R, Llovet JM. Modified RECIST (mRECIST) assessment for hepatocellular carcinoma. Semin Liver Dis. 2010 Feb;30(1): 52-60.

61 Zhu AX, Park JO, Ryoo BY, Yen CJ, Poon R, Pastorelli $\mathrm{D}$, et al. Ramucirumab versus placebo as second-line treatment in patients with advanced hepatocellular carcinoma following first-line therapy with sorafenib (REACH): a randomised, double-blind, multicentre, phase 3 trial. Lancet Oncol. 2015 Jul;16(7): 859-70.

62 Johnson PJ, Qin S, Park JW, Poon RT, Raoul JL, Philip PA, et al. Brivanib versus sorafenib as first-line therapy in patients with unresectable, advanced hepatocellular carcinoma: results from the randomized phase III BRISKFL study. J Clin Oncol. 2013 Oct 1;31(28): 3517-24.

63 Llovet JM, Decaens T, Raoul JL, Boucher E Kudo M, Chang C, et al. Brivanib in patients with advanced hepatocellular carcinoma who were intolerant to sorafenib or for whom sorafenib failed: results from the randomized phase III BRISK-PS study. J Clin Oncol. 2013 Oct 1;31(28):3509-16.
64 Zhu AX, Kudo M, Assenat E, Cattan S, Kang YK, Lim HY, et al. Effect of everolimus on survival in advanced hepatocellular carcinoma after failure of sorafenib: the EVOLVE-1 randomized clinical trial. JAMA. 2014 Jul 2; 312(1):57-67.

65 Santoro A, Rimassa L, Borbath I, Daniele B, Salvagni S, Van Laethem JL, et al. Tivantinib for second-line treatment of advanced hepatocellular carcinoma: a randomised, placebocontrolled phase 2 study. Lancet Oncol. 2013 Jan;14(1):55-63.

66 Bruix J, Qin S, Merle P, Granito A, Huang YH, Bodoky G, et al. Regorafenib for patients with hepatocellular carcinoma who progressed on sorafenib treatment (RESORCE): a randomised, double-blind, placebo-controlled, phase 3 trial. Lancet. 2017 Jan 7;389(10064): 56-66.

67 Kudo M, Finn RS, Qin S, Han KH, Ikeda K, Piscaglia F, et al. Lenvatinib versus sorafenib in first-line treatment of patients with unresectable hepatocellular carcinoma: a randomised phase 3 non-inferiority trial. Lancet. 2018 Mar 24;391(10126):1163-73.

68 Abou-Alfa GK, Meyer T, Cheng AL, ElKhoueiry AB, Rimassa L, Ryoo BY, et al. Cabozantinib in patients with advanced and progressing hepatocellular carcinoma. N Engl J Med. 2018 Jul 5;379(1):54-63.

69 Zhu AX, Kang YK, Yen CJ, Finn RS, Galle PR, Llovet JM, et al. Ramucirumab after sorafenib in patients with advanced hepatocellular carcinoma and increased $\alpha$-fetoprotein concentrations (REACH-2): a randomised, doubleblind, placebo-controlled, phase 3 trial. Lancet Oncol. 2019 Feb;20(2):282-96.

70 El-Khoueiry AB, Sangro B, Yau T, Crocenzi TS, Kudo M, Hsu C, et al. Nivolumab in patients with advanced hepatocellular carcinoma (CheckMate 040): an open-label, noncomparative, phase $1 / 2$ dose escalation and expansion trial. Lancet. 2017 Jun 24, 389(10088):2492-502.

71 Zhu AX, Finn RS, Edeline J, Cattan S, Ogasawara S, Palmer D, et al. Pembrolizumab in patients with advanced hepatocellular carcinoma previously treated with sorafenib (KEYNOTE-224): a non-randomised, openlabel phase 2 trial. Lancet Oncol. $2018 \mathrm{Jul}$; 19(7):940-52.

72 Faivre S, Rimassa L, Finn RS. Molecular therapies for HCC: looking outside the box. J Hepatol. 2020 Feb;72(2):342-52. 